\title{
Summary of: General dental practitioners' knowledge of polymerisation of resin-based composite restorations and light curing unit technology
}

\section{FULL PAPER DETAILS}

1*2Edinburgh Postgraduate Dental Institute The University of Edinburgh, Lauriston Buildings, Lauriston Place, Edinburgh, EH3 9HA ${ }^{*}$ Correspondence to: Dr Ario Santini

Email:ariosantini@hotmail.com

Online article number E13

Refereed Paper - accepted 21 July 2011

DOI: 10.1038/sj.bdj.2011.768

${ }^{\text {OB }}$ British Dental Journal 2011; 211: E13

\author{
A. Santini ${ }^{1}$ and S. Turner ${ }^{2}$
}

Objective Clinical successful use of resin-based composite restorations (RBCs) depends on knowledge of material and light curing unit (LCU) related factors. The purpose of this study was to evaluate general dental practitioners' knowledge of polymerisation of RBCs and LCU technology. Methods Members of the Active Research Group of the Faculty of General Dental Practice (UK) in England, Scotland and Wales engaged in primary dental care were sent a letter introducing the study and asking for their cooperation, followed by an email containing a link to the online survey questionnaire, hosted on Surveymonkey.com. The questionnaire enquired about current LCUs, and asked a series of questions on material science. Results Sixty-six percent of the 274 members contacted responded. Fifty-seven percent used LED units, 25\% quartz tungsten halogen (OTH), and 1\% plasma arc (missing: 17\%). Thirty percent reported having access to a radiometer. Appropriate responses regarding the degree of conversion of composite and adhesive materials were given by 32\% and 23\% respectively, and 22\% agreed that LED and QTH LCUs had comparable efficiency in polymerising composites. Thirty-three percent were aware that RBCs eluted substances that may have adverse local or systemic consequences. Fifty-eight percent stated that if polymerisation of RBC is slowed down, polymerisation stress will be lower, and $43 \%$ said that polymerisation shrinkage will be reduced if the degree of conversion is reduced. Knowledge (measured by appropriate responses to these questions) was not related to years since qualification $(r=-0.05, n=168, p=0.53)$. Conclusion The study suggests that dentists' knowledge of curing RBC restorations and LCUs is poor. This indicates that there is a need for training and guidance in this aspect of primary dental care.

\section{EDITOR'S SUMMARY}

I may be wrong and I may certainly be doing teachers of dental materials an injustice but was I alone in regarding this as one of the most tedious subjects in the dental school curriculum? Somehow the constituents of a material, its chemistry, setting characteristics, knoop hardness value and a host of other apparently fascinating features left me rather cold. What seemed important was the use to which they could be put in order to help treat a patient and solve a problem.

Now it may be that many of the dentists who participated in the survey outlined in this research paper had a similar opinion on dental materials either at dental school, or if they had qualified before the use of light cured resin-based composites was taught, then on postgraduate courses. Whatever the reason, this paper highlights the fact that the dentists questioned were significantly deficient in their knowledge of the handling and properties of light cured resin-based composites, which could well be to the detriment of the treatment they are carrying out. This is quite alarming given that composite resins are relatively technique-sensitive compared with other restorative materials and that their use is likely to continue to increase into the future.

Indeed, with the subject of banning the sale of mercury or mercury-based products being currently actively debated at the United Nations, and despite the FDI vigorously defending the use of amalgam on behalf of the profession, it may not be too long before amalgam is unavailable to us as a treatment option. It is therefore all the more important that research of this nature continues, but as importantly, that steps are taken to help bring practitioners up to speed on the use of these composites (and arguably others), their pitfalls as well as the advantages. It may be, like many other regularly practised routines, that familiarity breeds contempt (although length of time in practice had no discernable difference) but even if this is the case then the need for continuing guidance is all the most important.

The full paper can be accessed from the $B D J$ website (www.bdj.co.uk), under 'Research' in the table of contents for Volume 211 issue 6.

Stephen Hancocks Editor-in-Chief

DOI: 10.1038/sj.bdj.2011.791 


\section{TO ACCESS THE BDJ WEBSITE TO READ THE FULL PAPER:}

- BDA Members should go to www.bda.org.

- Click the 'login' button on the right-hand side and enter your BDA login details.

- Once you have logged in click the 'BDJ' tab to transfer to the BDJ website with full access.

IF YOUR LOGIN DETAILS DO NOT WORK:

- Get a password reminder: go to www.bda.org, click the login button on the right-hand side and then click the forgotten password link.

- Use a recommended browser: we recommend Microsoft Internet Explorer or Mozilla Firefox.

- Ensure that the security settings on your browser are set to recommended levels.

IF YOU HAVE NOT YET SIGNED UP TO USE THE BDA WEBSITE:

- Go to www.bda.org/getstarted for information on how to start using the BDA website.
IN BRIEF

- Gives readers a better understanding of the degree of conversion of composites and adhesives and the relationship between degree of conversion and polymerisation shrinkage.

- Readers should be aware that cured resinbased restorations can elute potentially toxic substances.

- Intensity of LCUs is not the most important factor. Total energy delivered is the product of intensity and time.

\section{COMMENTARY}

Light cured resin-based composites (RBCs), advances in adhesive materials and less invasive treatments have significantly influenced dental practice.

Santini and Turner have surveyed the knowledge of RBC polymerisation and light curing technology of dentists working in primary care. International and UK-based studies conclude that $\mathrm{RBC}$ restorations are not lasting as long as they should. The authors cite a possible reason as inadequate light curing unit (LCU) performance. They proposed individual dentists' operating practice and subject knowledge as possible contributing factors. Whilst it would be difficult to prove a direct relationship between 'under-curing' and clinical failure in any prospective randomised clinical trial for ethical reasons, it is interesting to note that a cross-sectional pilot study of simulated intra-oral curing published in the $B D J^{1}$ concluded that operator variability was critical to light curing efficacy. A recent Canadian study has confirmed the significance of poor operator technique and identified preparation location and LCU characteristics as important factors. ${ }^{2}$

The current survey was conducted with the corroboration of the FGDP(UK) in collaboration with the Edinburgh Postgraduate Dental Institute, The University of Edinburgh, which administered and analysed the data. Members of the Faculty Active Research Group in England, Wales and Scotland, all actively engaged in primary dental care, were contacted by letter introducing the study purpose and participating dentists were emailed a link to the online survey. The questionnaire addressed four topics relating to the respondents' LCU, related materials science and questions to do with the respondents' professional background and work status. As the survey was restricted to research group members of the FGDP, the findings were acknowledged to be unlikely to be representative of general dental practice or overall Faculty membership.

The author's premise that dentists with more practice experience would have better knowledge of material science was refuted, confirming earlier studies. They expected the respondents' subject knowledge should be better than the profession in general. They concluded that the poor subject knowledge scores indicated the need for training and guidance in this aspect of primary dental care.

\section{A. Shortall}

Reader in Restorative Dentistry,

The University of Birmingham

Dental School

1. Shortall A C, Harrington E, Patel H B, Lumley P J A pilot investigation of operator variability during intra-oral light curing. Br Dent J 2002 193: 276-280.

2. Price R B, Felix C M, Whalen J M. Factors affecting the energy delivered to simulated class I and class V preparations. J Can Dent Assoc 2010; 76: a94.

\section{AUTHOR QUESTIONS AND ANSWERS}

1. Why did you undertake this research? A previous published paper $^{1}$ concluded that further research was required to identify the level of understanding of material science by dental clinicians. This was therefore undertaken in a preliminary study in Scotland and reported at the IADR meeting ${ }^{2}$ in 2010. At that meeting the consensus opinion among the attendees, mostly lecturers in dental material science, was that in many undergraduate dental schools, the teaching of material sciences had been downgraded. There was a unanimous call for this trend to be reversed. This prompted a UK study, the subject of the current paper.

2. What would you like to do next in this area to follow on from this work?

I am working with colleagues to undertake a European wide survey based on the current questionnaire. In addition I have obtained funding which will allow a UK survey of LCUs and resin-based restorations in general practice.

1. McFadzean R W, Gibson E, Newcombe R F, Nataraja R, Santini A. Resin-based composites and dentine-bonding agents. Which, who and why? A study in the East of Scotland. Prim Dent Care 2009; 16: 59-66.

2. Santini A, Turner S. UK-GDPs' knowledge of light curing resin based composites materials. Dental Mater 2010; 26(Suppl 1). 